Jurnal Pemberdayaan: Publikasi Hasil Pengabdian kepada Masyarakat

Vol. 2, No. 2, Agustus 2018, Hal. 333-340

ISSN: 2088 4559; e-ISSN: XXXX-XXXX

DOI:

\title{
PENUMBUHAN KARAKTER ANAK USIA SEKOLAH BERBASIS MASJID MELALUI KULIAH KERJA NYATA (KKN) DI MASJID MUHAJIRIN, KECAMATAN WIROBRAJAN
}

\author{
Okka Adiyanto $^{1}$ dan Mahasiswa KKN Alternatif Divisi IV B. $1^{2}$ \\ Universitas Ahmad Dahlan Yogyakarta \\ Email: okka.adiyanto@ie.uad.ac.id
}

\begin{abstract}
ABSTRAK
Kelurahan Wirobrajan merupakan salah satu wilayah yang memiliki jumlah anak usia sekolah yang cukup banyak. Usia sekolah ini adalah usia yang rentan terhadap pengaruh negatif. Pendidikan karakter menjadi penting untuk menangkal pengaruh negatif tersebut. Masjid sebagai media dakwah efektif membentuk karakter anak usia sekolah. Salah satu masjid di wilayah Wirobrajan yang digunakan untuk KKN alternatif periode LXI yaitu Masjid Muhajirin satu komplek dengan SD Muhammadiyah Wirobrajan 3. Metode yang digunakan yaitu pendidikan masyarakat, difusi IPTEK, dan juga praktek. Segala kegiatan pada KKN ini dilakukan di masjid sehingga suasana masjid akan semakin meriah. Hasil dan dampaknya, program-program sudah dilaksanakan dengan baik dan lancar serta sangat berperan dalam penumbuhan pendidikan karakter anak usia sekolah yang berbasis masjid.
\end{abstract}

Kata kunci: Pemberdayaan, Karakter, Masjid, KKN

\begin{abstract}
Wirobrajan is one of the regions with a large number of school-age children. The school-age age is one of the ages that is vulnerable to negative influences. Character education is an important one to counteract these negative influences. The mosque has become one of the effective media that can build the character of schoolage children. One of the mosques in the Wirobrajan area that was used for the alternative KKN for the LXI period was the Muhajirin Mosque. Muhajirin Mosque is located in a SD Muhammadiyah Wirobrajan 3 complex. This KKN program uses several methods used to ibuild character education. The method used is community education, the diffusion of science and technology, and also practice. All activities at this KKN are carried out in the mosque so that the atmosphere of the mosque will be more festive. The programs that have been implemented also play an important role in the growth of mosque-based school-age character education.
\end{abstract}

Keywords: Empowerment, Character, Mosque, KKN 


\section{PENDAHULUAN}

Kelurahan Wirobrajan merupakan salah satu kelurahan yang terletak di Kecamatan Wirobrajan. Jumlah penduduk di Kecamatan Wirobrajan pada tahun 201827.796 jiwa. Menurut sejarah, nama Wirobrajan berasal dari nama sebuah kesatuan prajurit kraton yang tinggal di wilayah tersebut yaitu Prajurit Wirabraja (Suwito, 2008). Kelurahan Wirobrajan memiliki 12 RW dan 58 RT dan jumlah penduduk untuk wilayah kelurahan Wirobrajan menurut data informasi kependudukan Provinsi Daerah Istimewa Yogyakarta berjumlah 9.323 jiwa. Batas-batas wilayah Kelurahan Wirobrajan yaitu :

Utara : Kelurahan Pakuncen

Timur : Kelurahan Notoprajan

Selatan : Kelurahan Patangpuluhan

Barat : Kelurahan Ngestiharjo

Kelurahan Wirobrajan memiliki jumlah penduduk usia sekolah lebih banyak dari pada wilayah kelurahan yang lain di wilayah Kecamatan Wirobajan. Data jumlah penduduk usia sekolah dapat dilihat pada Gambar 1.

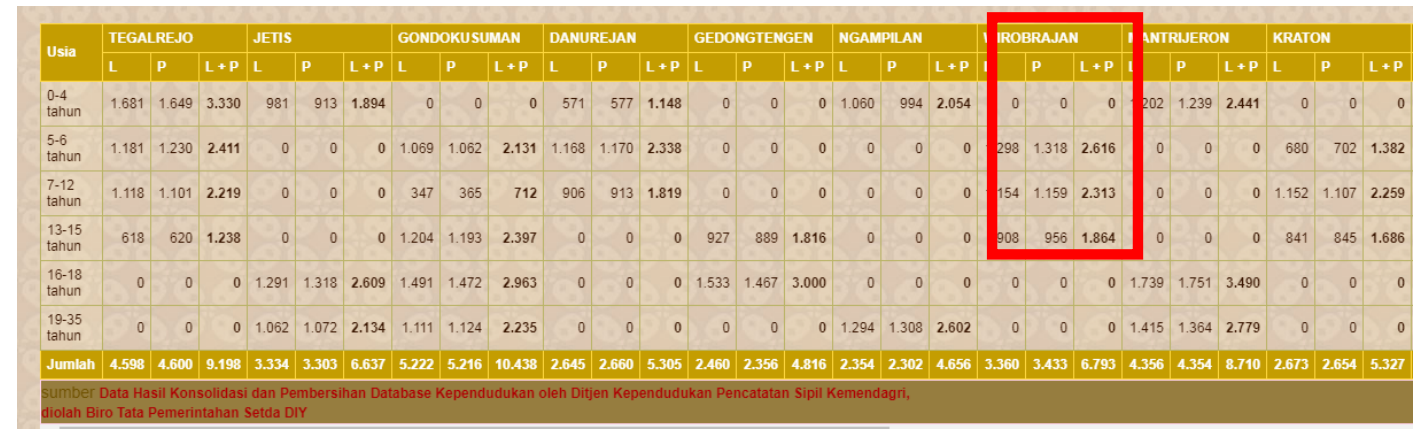

Sumber: kependudukan.jogjaprov.go.id

\section{Gambar 1 Data jumlah penduduk usia sekolah Kelurahan Wirobrajan}

Dari gambar tersebut dapat diartikan bahawa usia sekolah di Kelurahan Wirobrajan memerlukan pendampingan sehingga memiliki karakter yang sesuai dengan Perpres No 78 tahun 2017 tentang penguatan pendidikan Karakter (PPK). Menurut Fanhas \& Mukhlis (2017) ada tiga pokok peranan yang bersifat saling terkait dan fundamental untuk menuju pendidikan karkater tersebut yaitu Negara, agama, dan keluarga. Penduduk Indonesia mayoritas muslim yang mengajarkan pendidikan karakter berlandasakan Al Qur;an dan Al Hadits. Pelajaran karakter islami yang mudah ditemui salah satunya pendidikan karakter yang dilakukan di masjid.

Masjid menjadi salah satu tempat media dakwah yang efektif yang dapat membentuk karakter anak usia sekolah. Salah satu masjid di wilayah Wirobrajan yang digunakan untuk 
KKN alternatif periode LXI yaitu Masjid Muhajirin. Masjid Muhajirin terletak satu komplek dengan SD Muhammadiyah Wirobrajan 3. Beberapa permasalahan yang ditemukan dilokasi dantaranya adalah kegiatan TPA di Masjid Muhajirin yang tidak dapat berjalan secara intensif. Permasalahan tersebut disebabkan olek karena kurangnya peran remaja dalam mengurus masjid. Hal ini menunjukkan bahwa pendidikan karakter berperan penting dalam kemakmuran masjid. Kegiatan KKN ini berfokus pada pendidikan karakter anak sekolah untuk memakmurkan masjid terutama Masjid Muhajirin dengan kegiatan yang edukatif dan menyenangkan.

\section{METODE}

Beberapa metode yang diterapkan untuk dapat mencapai tujuan dari KKN Alternatif di wilayah Masjid Muhajirin Universitas Ahmad Dahlan Periode LXI yaitu dengan pendidikan masyarakat, difusi IPTEK atau pengenalan teknologi dan praktek. Ringkasan metode pelaksanaan dapat dilihat pada Tabel 1 .

Tabel 1 Ringkasan kegiatan dan keterlibatan mahasiswa

\begin{tabular}{|c|c|c|c|c|}
\hline No & Metode & Kegiatan & JKEM & $\begin{array}{c}\text { Jumlah } \\
\text { mahasiswa yang } \\
\text { terlibat }\end{array}$ \\
\hline \multirow{2}{*}{1} & \multirow{2}{*}{$\begin{array}{l}\text { Pendidikan } \\
\text { masyarakat }\end{array}$} & $\begin{array}{l}\text { Mengadakan pelatihan pembuatan } \\
\text { susu kedelai bagi remaja }\end{array}$ & $\begin{array}{l}2 \times 150 \\
\text { menit }\end{array}$ & 27 \\
\hline & & $\begin{array}{l}\text { Menyelenggarakan bimbingan belajar } \\
\text { agama setiap hari }\end{array}$ & $\begin{array}{l}20 \times 50 \\
\text { menit }\end{array}$ & 27 \\
\hline \multirow[t]{2}{*}{2} & \multirow{2}{*}{$\begin{array}{l}\text { Difusi iptek/ } \\
\text { Pengenalan } \\
\text { Teknologi }\end{array}$} & $\begin{array}{l}\text { Menyelenggarakan penyuluhan } \\
\text { Kesehatan untuk Jamaah Masjid } \\
\text { Muhajirin }\end{array}$ & $\begin{array}{l}2 \times 200 \\
\text { menit }\end{array}$ & 27 \\
\hline & & $\begin{array}{l}\text { Menyelenggarakan pemutaran video } \\
\text { edukasi }\end{array}$ & $\begin{array}{l}3 \times 300 \\
\text { menit }\end{array}$ & 27 \\
\hline \multirow{2}{*}{3} & \multirow{2}{*}{ Praktek } & $\begin{array}{l}\text { Mengadakan kebersihan Masjid dan } \\
\text { penataan alat Ibadah }\end{array}$ & $\begin{array}{l}2 \times 100 \\
\text { menit }\end{array}$ & 27 \\
\hline & & $\begin{array}{l}\text { Mengadakan Keputrian untuk Jamaah } \\
\text { Perempuan }\end{array}$ & $\begin{array}{l}2 \times 100 \\
\text { menit }\end{array}$ & 27 \\
\hline
\end{tabular}




\section{HASIL, PEMBAHASAN, DAN DAMPAK}

Program-program KKN Alternatif Divisi IV B.1 Univeritas Ahmad Dahlan yang sudah berjalan di bidang keilmuan, keagamaan, seni dan olahraga, dan tematik non tematik hasilnya pun sudah baik. Kriteria baik ini ditunjukkan dengan adanya peningkatan antusias masyarakat untuk mendatangi masjid dan solat berjamaah. Kegiatan-kegiatan yang bertujuan untuk meningkatkan pendidikan karakter anak usia sekolah dan sudah terlaksana yaitu TPA, pelatihan pembuatan susu kedelai bagi remaja putri, pelaksanaan keputrian, kegiatan kebersihan masjid, jalan-jalan keraton, pemutaran video edukasi, dll

TPA di Masjid Muhajirin tadinya dilaksanakan hanya tiga hari yaitu hari jum'at, sabtu dan minggu menjadi dilaksanakan setiap malam di masjid. Materi TPA yang diberikan juga sangat bervariasi, diantaranya tentang cerita nabi, hafalan surat, hafalan doa pendek, tajwid, cerdas cermat agama. Tambahan belajar umum juga diberikan untuk anak-anak seperti bimbingan belajar Matematika, Bahasa Inggris, tematik SD, dan lain-lain. Aktivitas TPA dan bimbingan belajar dapat dilihat pada Gambar 2 .
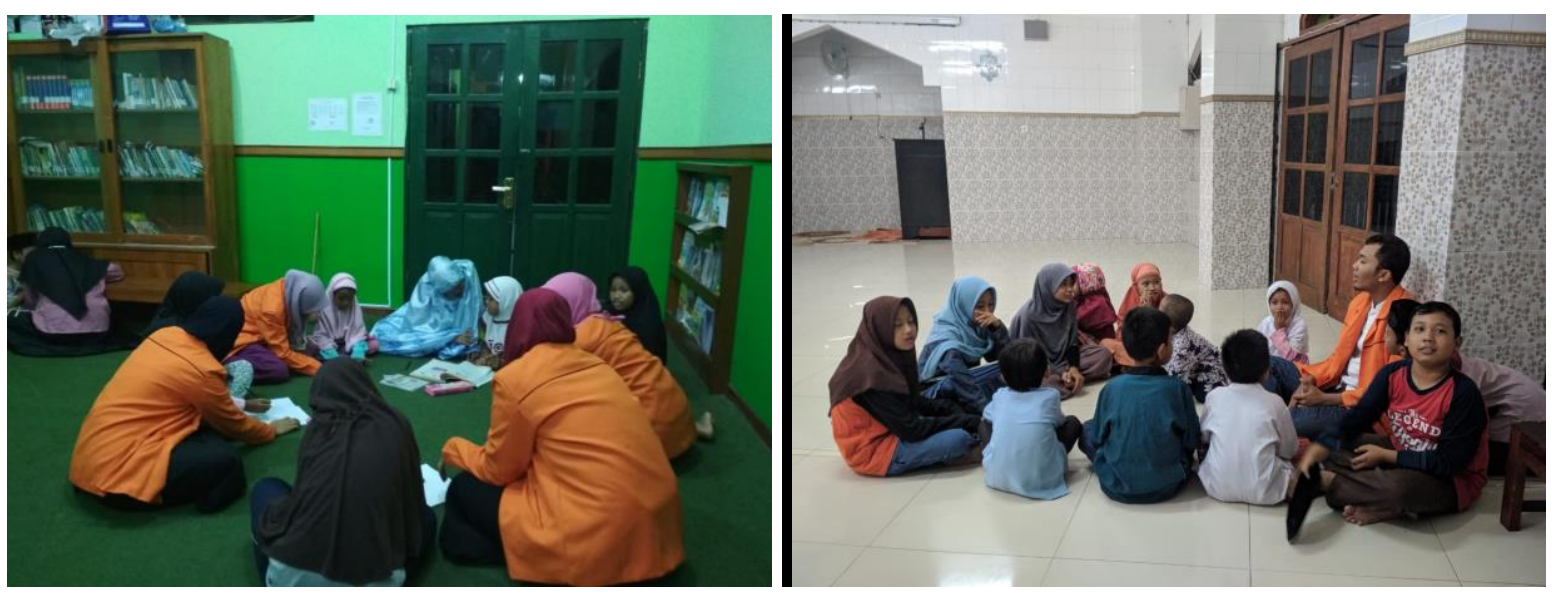

Gambar 2 Bimbingan TPA dan Belajar

Pelaksanaan Keputrian untuk jamaah putri masjid Muhajirin juga mendapatkan respon yang baik. Pelaksanaan keputrian ini merupakan cara belajar baru bagi jamaah putri yang berisi mengenai kajian keputrian, kisah inspiratif kehidupan, dan lain-lain yang berhubungan dengan keputrian. Selain program keputrian, mahasiswa KKN juga mengadakan sosialisasi pembuatan susu kedelai. Kegiatan ini diharapkan dapat meningkatkan kemampuan dalam keterampilan mmenciptakan karya yang juga bisa membantu perekonomian jamaah masjid. Gambar sosialisasi pembuatan susu kedelai dapat dilihat pada Gambar 3. Dampak dari kegiatan ini jamaah Masjid Muhajirin dapat membuat susu kedelai yang dapat digunakan untuk menaikkan taraf perekonomian jamaah. 


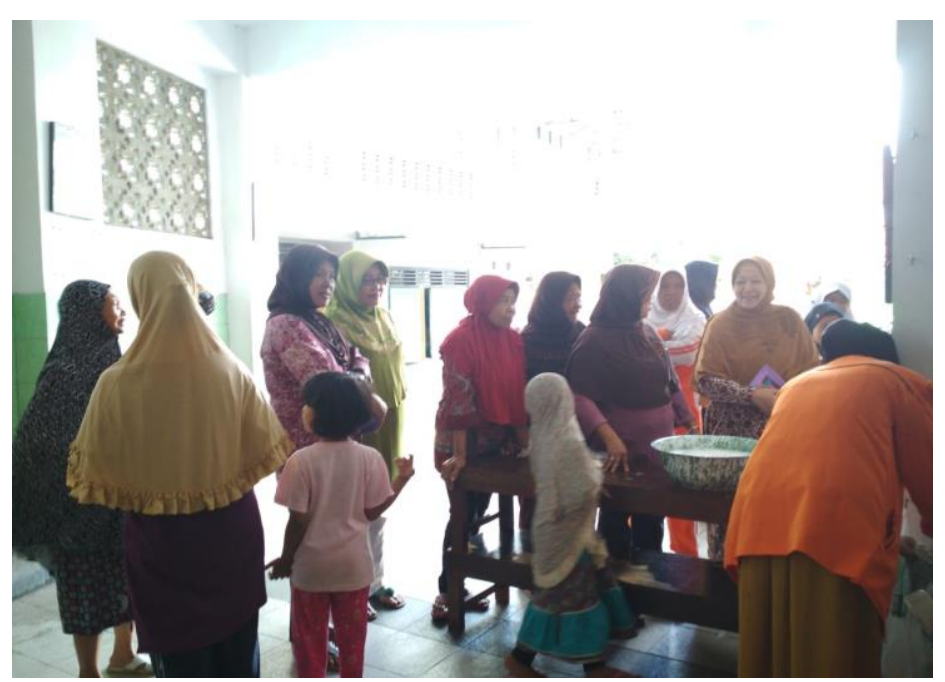

Gambar 3 sosialisasi pembuatan susu kedelai

Program selanjutnya merupakan bersih-bersih masjid. Program ini merupakan program yang ditujukan untuk anak-anak TPA agar lebih cinta kepada masjid dan menjaga kebersihan masjid. Kegiatan kebersihan dan mengatur kembali alat ibadah yang ada dimasjid bertujuan untuk menambah kenyamanan dalam beribadah dan sekaligus mengorganisir barang-barang yang masih terpakai dan yang sudah harus diperbaiki atau diganti. Gambar kegiatan bersih-bersih masjid dapat dilihat pada Gambar 4.

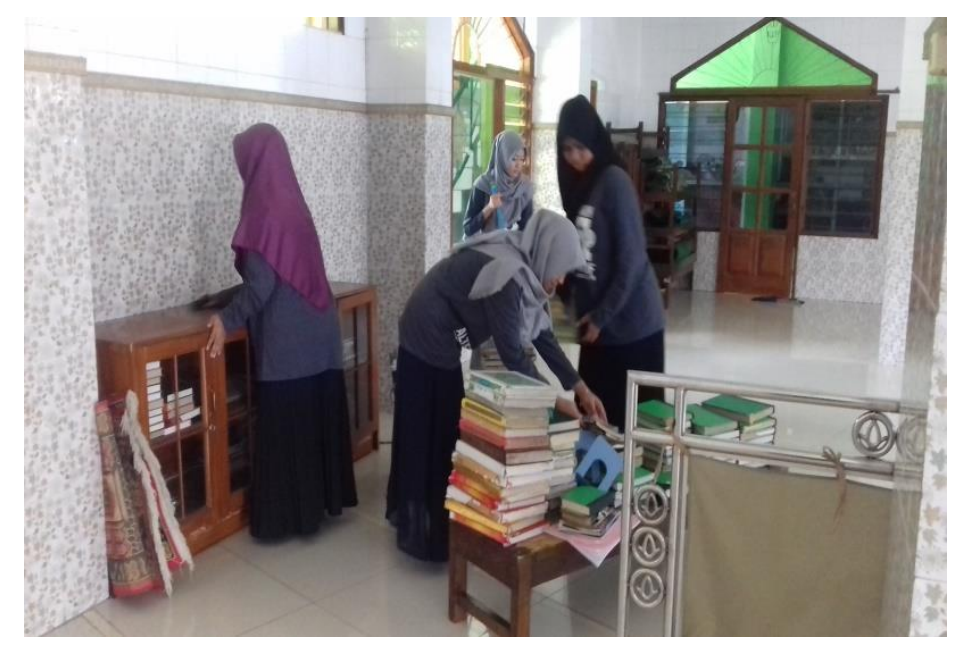

Gambar 4 Kegiatan bersih-bersih masjid

Program pendidikan karakter yang dilakukan selanjutnya yaitu jalan-jalan keraton. Kegiatan ini dilaksanakan untuk anak-anak TPA Masjid Muhajirin. Rihlah atau jalan-jalan rekreasi ke Keraton Yogyakarta. Dipilihnya Kraton Yogyakarta dikarenakan ingin menunjukkan sejarah masa lalu. Keraton Yogya merupakan kerajaan Islam di Tanah Jawa yang memiliki tradisi yang baik. Hal ini semoga bisa memberikan pengalaman yang unik sekaligus pengalaman yang menyenangkan di samping pengalaman untuk mengenal sejarah 
kraton Yogyakarta. Peserta kegiatan rihlah ini mengaku sangat senang karena dapat mengetahui sejarah-sejarah bangsa Indonesia pada umumnya dan juga penyebaran agama Islam di Yogyakarta.

Program unggulan yang menjadi program bersama di tingkat Kecamatan yaitu Gebyar Anak Sholeh (GAS). Tujuan dari GAS tersebut yaitu untuk memfasilitasi bibit-bibit unggul dari masing-masing TPA sebagai ajang unjuk kemampuan potensi yang ada pada diri santri. Adapun pelaksanaan GAS tersebut berisi lomba-lomba keislaman meliputi Cerdas Cermat Agama (CCA), tartil, adzan, hafalan juz'amma, mewarnai dan menggambar islami, serta dilanjutkan cerita anak sholeh oleh diisi oleh Kak Aris Pahlawan Bertopeng. Gambar dari festival anak soleh dapat dilihat pada Gambar 5.

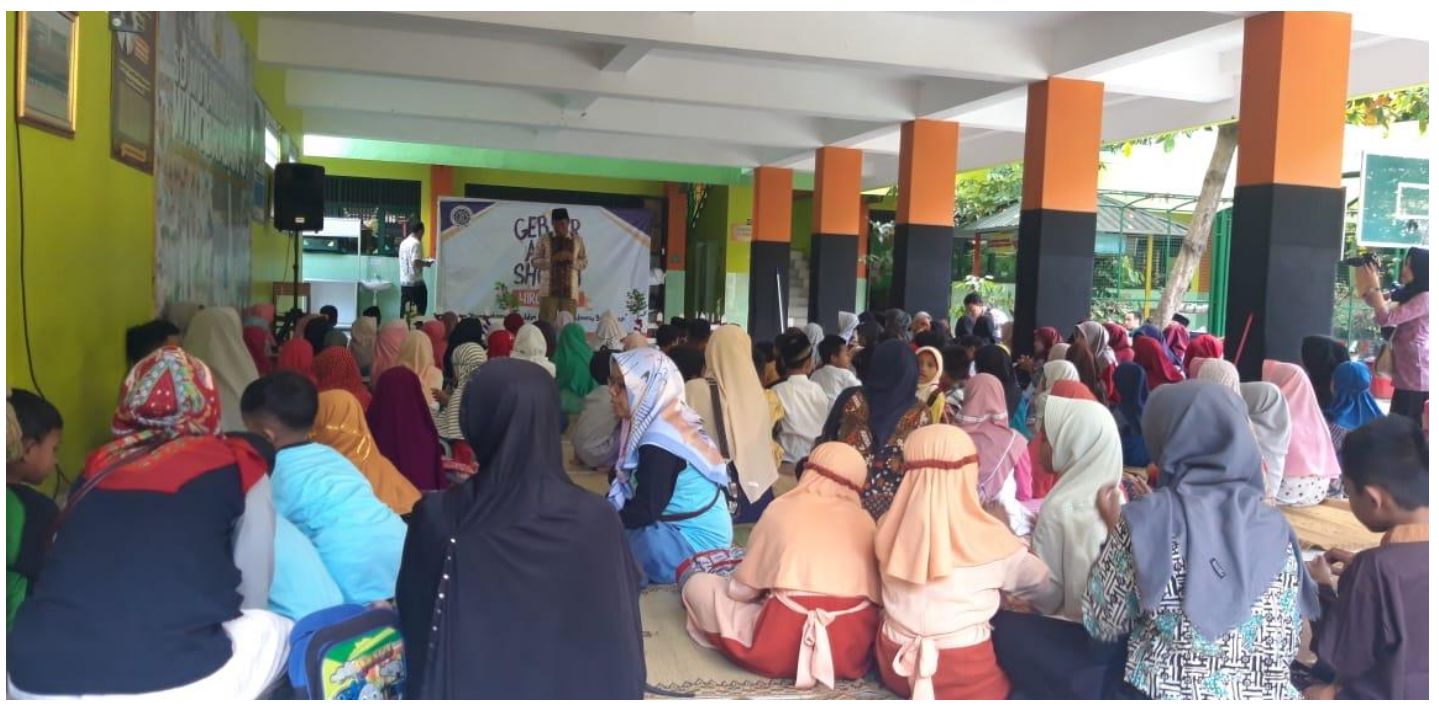

Gambar 5 Gebyar Anak Sholeh (GAS)

Selain kegiatan-kegiatan mahasiswa KKN, ada juga kegiatan yang digagas oleh Pimpinan Cabang Muhammadiyah (PCM) wirobrajan yang bertajuk Muhammadiyah Expo 2018. Pada kegiatan ini berisi talkshow dan juga bazar. Pada talkshow yang bertajuk "Mata Yoga" ini mengambil tema jejaring ranting Se PCM Wirobrajan. Tujuan dari Muhammadiyah Expo 2018 ini sebagai salah satu wujud untuk ajang silahturahmi warga Muhammadiyah se Cabang Wirobrajan. Foto agenda dri talkshow dapat dilihat pada Gambar 6 dan Gambar 7. 


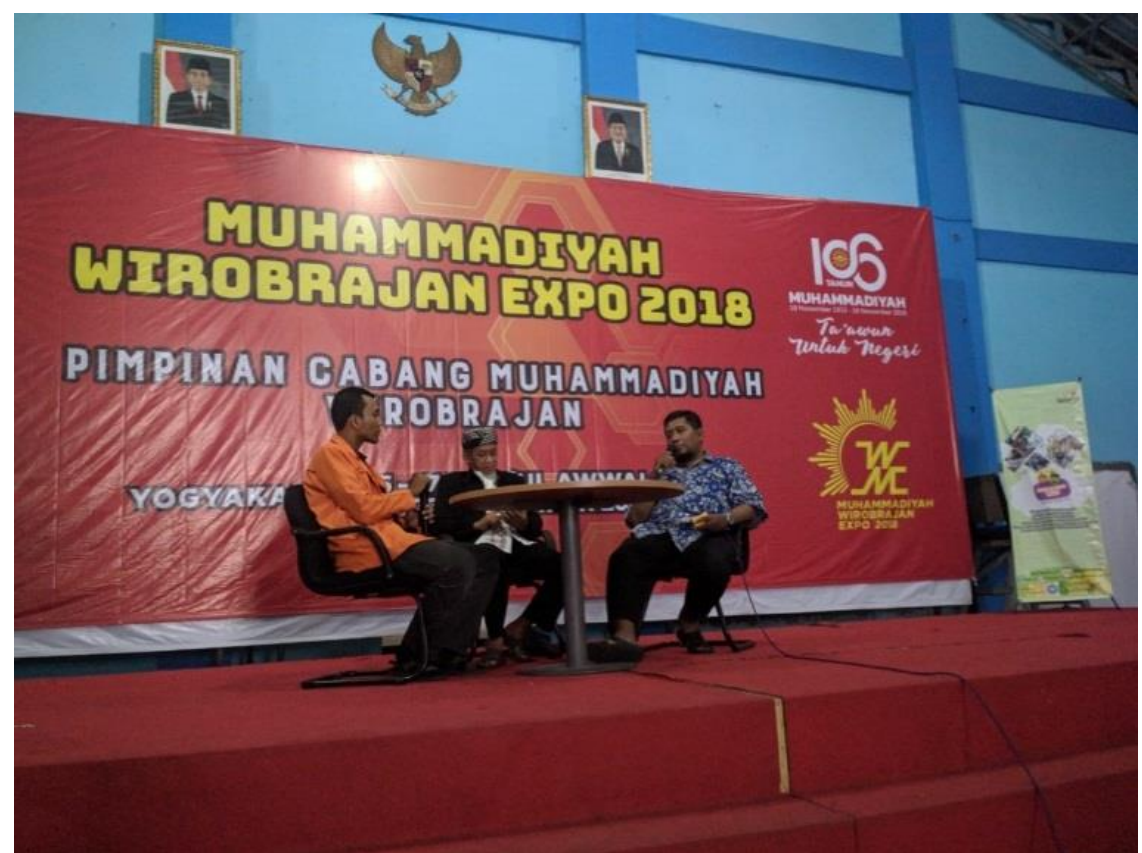

Gambar 6 talkshow 'Mata Yoga”

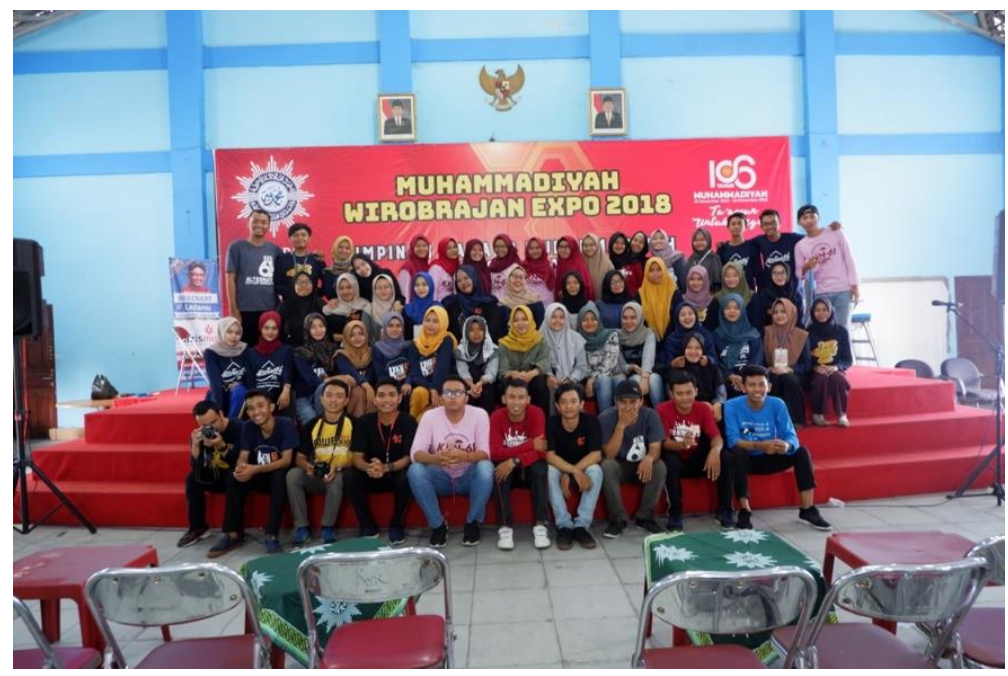

Gambar 7 Muhammadiyah Wirobrajan Expo 2018

\section{SIMPULAN}

Program KKN UAD adalah memberdayakan masyarakat Kelurahan Wirobrajan dalam program kegiatan masjid. Program ini dapat berkolaborasi dengan baik dengan pihak masjid dan bermanfaat bagi seluruh pihak yang terkait. Kegiatan-kegiatan yang sudah dilaksanakan juga sangat berperan dalam penumbuhan pendidikan karakter anak usia sekolah yang berbasis masjid. 


\section{DAFTAR PUSTAKA}

Fanhas, E., \& Mukhlis, G. N. (2017). Pendidikan karakter untuk anak usia dini menurut Q.S. Lukman 13-19. PEDAGOGI : Jurnal Anak Usia Dini dan Pendidikan Anak Usia Dini , 3 (3a).

Perpres No 78 tahun 2017.

Suwito, Yuwono Sri. (2008). Prajurit Kraton Yogyakarta: Filosofi dan Nilai Budaya yang Terkandung di Dalamnya. Yogyakarta: Dinas Pariwisata dan Kebudayaan Yogyakarta http://www.kependudukan.jogjaprov.go.id/

\section{UCAPAN TERIMAKASIH}

Terima kasih kepada Lembaga Penelitian dan Pengabdian kepada Masyarakat (LPPM) Universitas Ahmad Dahlan yang telah memberikan segala bantuan di KKN Alternatif periode LXI. Terima kasih juga kepada takmir Masjid Muhajirin yang sudah memberikan segala bantuan sampai berakhirnya KKN Alternatif ini. 